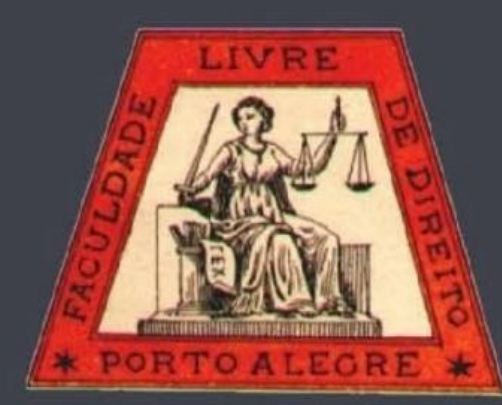

\title{
Tributação, economia e Constituição: o planejamento tributário no contexto brasileiro
}

Taxation, economy and Constitution: tax planning in the Brazilian context

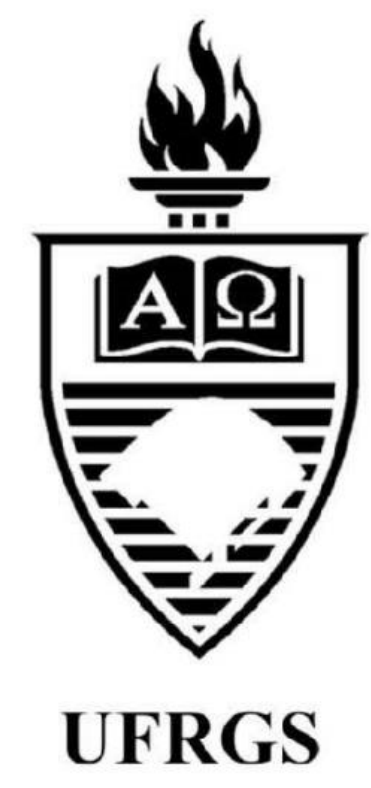

Gabriel Campos Soares da Fonseca Universidade de Brasília

Rafael Campos Soares da Fonseca Instituto Brasiliense de Direito 


\title{
Tributação, economia e Constituição: o planejamento tributário no contexto brasileiro
}

\author{
Taxation, economy and Constitution: tax planning in the Brazilian context
}

Gabriel Campos Soares da Fonseca*

Rafael Campos Soares da Fonseca**

\section{REFERÊNCIA}

FONSECA, Gabriel Campos Soares da; FONSECA, Rafael Campos Soares da. Tributação, economia e Constituição: o planejamento tributário no contexto brasileiro. Revista da Faculdade de Direito da UFRGS, Porto Alegre, n. 36, vol. esp., p. 247-265, out. 2017.

\section{RESUMO}

O presente artigo busca realizar uma investigação acerca do planejamento tributário, em especial, visando os seus desdobramentos no contexto brasileiro. Para tanto, utilizou-se da metodologia de análise bibliográficodoutrinária e de acórdãos produzidos pelo CARF com foco no caso ARCELORMITTAL. Perpassou-se pelos delineamentos do sistema constitucional tributário brasileiro para, então, em um segundo momento, analisar a ambivalência principiológica presente nele e sua decorrente tensão entre princípios. Outrossim, é, também, válido observar as teorias "Clássica" e "Moderna", pois valoram de forma diferente tais princípios e, logo, trazem sérios impactos ao planejamento tributário. Á vista disso, por fim, tornou-se essencial concluir pela fixação de parâmetros conceituais mais sólidos a fim de garantir a necessária segurança jurídica do contribuinte e viabilizar a elisão fiscal.

\section{PALAVRAS-CHAVE}

Planejamento Tributário. Tributação Internacional. CARF. Direito Constitucional Tributário.

\begin{abstract}
This paper aims to realize an investigation about the tax planning practice in the Brazilian context. Therefore, this paper utilized bibliographic analysis methodology and also analyzed some decisions made by the CARF focusing on the ARCELORMITTAL'S case. First, it was necessary to go through the Brazilian constitutional tax system to then analyze the "principiological ambivalence" within it and its consequent principiological tension. Furthermore, it is also valid to understand better the "Classic" and the "Modern" theories, given that they value these principles differently, thus bringing important impacts to tax planning. Therefore, it was also essential to conclude that was necessary to establish more robust conceptual parameters in order to ensure the necessary legal certainty to the taxpayer and enable tax planning.
\end{abstract}

\section{KEYWORDS}

Tax Planning. International Taxation. CARF. Constitutional Tax Law.

\section{SUMÁRIO}

Introdução. 1. Apontamentos acerca do Sistema Constitucional Tributário brasileiro. 2. Ambivalência principiológica e a tensão entre princípios. 2.1. Proteção ao Contribuinte x Arrecadação Fiscal. 2.2. O Direito a Economia de Tributos e a Solidariedade Social. 3. Interpretação da norma e do planejamento tributário. 4. Um estudo de caso sobre os lucros auferidos no exterior em virtude de participação societária. 4.1 O Caso ARCELORMITTAL. 4.2. A Instabilidade Jurisprudencial no Âmbito Contencioso Administrativo. Considerações Finais. Referências.

\footnotetext{
* Graduando em Direito pela Universidade de Brasília (UnB). Visiting Student em "Democrazia e Sviluppo" na Università degli Studi di Siena (UniSi-Itália). Pesquisador do Centro Brasileiro de Estudos Constitucionais (CBEC - UniCeub) e do Centro de Pesquisa em Direito Constitucional Comparado da UnB.

*** Professor do Instituto Brasiliense de Direito Público (IDP). Mestre em Direito, Estado e Constituição pela Universidade de Brasília (UnB). Ex-Membro do Conselho Editorial e atual membro do Conselho Revisor da Revista dos Estudantes de Direito da UnB. Assessor de Ministro do Supremo Tribunal Federal (STF).
} 


\section{INTRODUÇÃO}

O presente artigo busca delinear e adentrar nos principais problemas acerca do planejamento tributário tendo como foco o contexto brasileiro, partindo-se da metodologia da análise bibliográfica e da jurisprudência administrativa em questão.

Haja vista as novas dinâmicas societárias de um mundo cada vez mais globalizado, a tributação, em nível internacional, e as estratégias de "engenharia tributária" ${ }^{1}$ tornaram-se centrais no debate acerca do planejamento tributário. A primeira parte do trabalho almeja perpassar pelo sistema constitucional tributário brasileiro, pois toda a atividade tributária deve estar submetida a ele. Dessa forma, avaliam-se as consequências das particularidades do desenvolvimento histórico do sistema brasileiro observando-o como um sistema rígido de competências que, assim, elucida uma série impactos no recorte específico do planejamento tributário e na própria prática da tributação.

Após uma atenta análise acerca do sistema constitucional tributário, na segunda parte do trabalho, busca-se propagar a ideia de que é possível perceber uma ambivalência principiológica na nossa Constituição, em especial, no que tange ao âmbito tributário. Essa ambivalência trouxe uma tensão entre princípios que tem gerados sérios embates em relação à extensão da legitimidade da arrecadação fiscal em face da proteção do contribuinte, bem como da discussão da existência de um válido e legítimo direito a economizar tributos por parte desse.

Essa constatação permite demonstrar um contraste de teorias acerca da interpretação da

\footnotetext{
1 "Assim, ousamos definir engenharia tributária como aptidão para escolha das formas jurídicas mais adequadas ao exercício da atividade econômica com o menor ônus tributário." MACHADO, Hugo de Brito. Introdução ao Planejamento Tributário. São Paulo: Malheiros, 2014, p. 74. 2 MINISTÉRIO DA FAZENDA - CONSELHO ADMINISTRATIVO DE RECURSOS FISCAIS. Recurso
}

norma tributária e do planejamento tributário. Assim, na terceira parte do trabalho, intenta-se expor os desdobramentos da teoria dita como "Clássica" e da teoria vista como "Moderna", pois valorizam e tratam tais princípios de forma distinta. Por conseguinte, de acordo com a teoria hermenêutica que o julgador filia-se, altera-se a visão acerca do combate ou incentivo ao planejamento tributário.

$\mathrm{Na}$ quarta parte, busca-se estabelecer um arcabouço teórico que permita delimitar, corretamente, as formas jurídicas empregadas como verdadeiras limitações ao planejamento tributário. Ainda, diferenciá-las a fim de construir, a partir da análise metodológica bibliográfica e doutrinária, um adensamento teórico sólido que permita um melhor estudo dos casos práticos as envolvendo. Visando um embasamento empírico, real e prático do presente trabalho, a última parte do artigo busca debruçarse na análise das nuances dos julgados do CARF. Assim, tendo como foco o caso recorrido na $3^{\mathrm{a}}$ Turma da DRJ/SPO envolvendo o grupo Arcelormittal Tubarão Comercial S/A. ${ }^{2}$

Por fim, o presente trabalho conclui pela necessidade de uma reforma dos institutos de desconsideração do planejamento tributário e da utilização desses no âmbito do CARF. Isso, pois, à luz de uma compatibilização entre as teorias "Moderna" e "Clássica", dando enfoque à teoria dita como "Clássica". Assim, tendo em vista sua pouca utilização na atualidade, é preciso resgatar certos elementos a fim de propagar padrões mínimos de segurança jurídica. Para com isso, por fim, tentar viabilizar a prática da correta elisão fiscal, do planejamento tributário e da economia de tributos.

Voluntário: Processo n ${ }^{\circ} 16643.000326 / 2010-91$ Acórdão n $^{\circ}$ 1402-001.875. $4^{\text {a }}$ Câmara/ $2^{\text {a }}$ Turma Ordinária. Relator: Cons. Fernando Brasil de Oliveira Pinto. Julgado em: 26/11/2014. S1- C472 FL. 905. Impresso em: 30/06/2015 por Receita Federal. 


\section{APONTAMENTOS ACERCA DO SISTEMA TRIBUTÁRIO BRASILEIRO}

O contexto internacional tem impactos significativos nos diversos sistemas tributários existentes. A despeito disso, no tocante ao Brasil, é preciso realizar um recorte metodológico preciso e atento às nuances e especificidades deste sistema. Diversos países, ao redor do mundo, possuem Constituições que dizem respeito apenas aos princípios básicos do Direito Tributário e/ou aos elementos gerais desse. ${ }^{3}$

Todavia, no Brasil, o constituinte buscou reter o poder tributário pleno sendo meticuloso e extenso, assim concedendo à legislatura ordinária competências mais restritas e específicas. A partir de uma discriminação de rendas rígida e a abrangência das normas constitucionais, percebemos, segundo Geraldo Ataliba, que o sistema constitucional tributário brasileiro é rígido $^{4}$, pois distribui as devidas competências por meio de regras evidenciando, para o autor, a rigidez do sistema constitucional tributário como um princípio constitucional implícito. 5 Consequentemente, a divisão rígida de competências traz sérias implicações para a tributação. O sistema constitucional tributário do Brasil estabelece, por exemplo, a privatividade das competências tributárias em relação aos impostos, às taxas e à contribuição de melhoria ${ }^{6}$.

A importância dessa característica é extremamente vasta e demonstra a indispensabilidade do estudo da Constituição para melhor compreendermos as questões tributárias.

\footnotetext{
${ }^{3}$ Ver: Artigo $1^{\circ}$ da Seção 8 da Constituição dos Estados

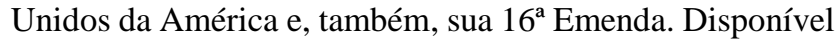
em:

http://www.senate.gov/civics/constitution_item/constitutio n.htm

${ }^{4}$ ATALIBA, Geraldo. Sistema Constitucional Tributário Brasileiro. São Paulo: Revista dos Tribunais, 1968, p. 38

5 ATALIBA, Geraldo. Sistema Constitucional Tributário

Brasileiro. São Paulo: Revista dos Tribunais, 1968, p. 67
}

Para suscintamente exemplificarmos essa centralidade, é preciso observar que as nações organizadas, a partir de suas disposições constitucionais, sob a forma de federação ou confederação, ao redor do mundo, demonstram a existência de disputas acerca da arrecadação dos tributos entre as entidades do Poder Público ${ }^{7}$.

No entanto, no contexto brasileiro, a deflagração de conflitos de competências entre os entes federados é um fenômeno cada vez mais presente, visível e grave graças às suas especificidades. A Guerra Fiscal - prática adotada pelos Estados, em matéria tributária, para atrair empresas para os seus territórios - especialmente no que toca o contexto do ICMS, é exemplo notório e vívido de um dos problemas decorrentes dessa divisão rígida e da relevância que essa divisão exerce para o sistema e para seu funcionamento.

Por conseguinte, após um breve adensamento teórico, percebe-se que não é possível uma transplantação simplista de fórmulas e institutos estrangeiros para realidade brasileira, isto é, a doutrina, na realidade, deve ser construída à luz da nossa realidade política, social e jurídica para que seja possível fornecer respostas substanciais aos problemas postos no devido contexto ${ }^{8}$ e realizar, com a devida cautela, a incorporação de institutos jurídicos estrangeiros.

O planejamento tributário exerce papel central na prática tributária brasileira e no próprio estudo desta, assim, o seu entendimento perpassa, também, pelos delineamentos constitucionais. Portanto, a existência, a restrição e o combate ao planejamento tributário estão intimamente

6 CARrAZA, Roque Antônio. Curso de Direito Constitucional Tributário. 28 ${ }^{a}$ ed. São Paulo: Malheiros, 2012, pp. 670-681.

${ }^{7}$ MACHADO, Hugo de Brito. Proibição da guerra fiscal e a redução das desigualdades regionais. In: ROCHA, Valdir de Oliveira (org). Grandes questões atuais do Direito Tributário. $15^{\circ}$ volume. São Paulo: Dialética, 2011, p. 125. 8 ATALIBA, Geraldo. Sistema Constitucional Tributário Brasileiro. São Paulo: Revista dos Tribunais, 1968, p. 37 
interligados à interpretação e à valoração das regras e dos princípios estabelecidos pela Constituição Federal de 1988. Desse modo, é imprescindível que se analise as principais problemáticas em torno do sistema constitucional brasileiro à vista de suas consequências e suas implicações para o planejamento tributário como um todo.

\section{AMBIVALÊNCIA PRINCIPIOLÓGICA E A TENSÃO ENTRE PRINCÍPIOS}

\subsection{Proteção ao Contribuinte $x$ Arrecadação Fiscal}

À vista do contexto de redemocratização do Brasil e, em especial, de sua Assembleia Nacional Constituinte, via-se uma Constituinte Popular. Nessa, imperava um modelo de ampla deliberação e de uma série de confrontos e conflitos argumentativos de grupos, muitas vezes, extremamente, divergentes.

Assim, nesse âmbito de heterogeneidade, elucidava-se um arcabouço de funcionamento amplamente descentralizado no qual se ensejou, por consequência, no interior do Congresso Nacional, uma participação de diversos atores extraparlamentares ${ }^{9}$. Observava-se, então, na ocasião, os mais variados segmentos da sociedade percebendo-se, assim, lado-a-lado, por exemplo, interesses corporativistas e movimentos sociais de forma que ambos exerciam suas atividades pressionando o processo de elaboração da Constituição Federal de 1988.

Essa realidade, consequentemente, trouxe sérias implicações para o Direito como um todo e, em especial, para o resultado final da Constituição. A partir do próprio contexto de heterogeneidade propagado pela constituinte brasileira e a presença de grupos com vontades e demandas divergentes, a Constituição de 1988 firmou, em seu texto, a previsão de interesses diversos abrangendo vários grupos e várias concepções. Pode-se verificar diferentes visões e valorações acerca da prática da tributação as quais foram expostas no texto constitucional.

Nota-se, portanto, uma espécie de ambivalência principiológica que gera, em nãoraros casos concretos, uma tensão entre princípios constitucionais. Destarte, as limitações constitucionais ao poder de tributar e garantias aos indivíduos, diversas vezes, chocam-se e com as demandas sociais que exigem tributação para concretizá-las concretizando interpretações conflitantes acerca de um mesmo fato. A Carta Maior limita o poder do Estado em favor do contribuinte perpetuando "obrigações negativas", mas, concomitantemente, também, obriga o Estado a atuar de maneira positiva para concretizar as demandas previstas no ordenamento constitucional.

Os princípios previstos na Constituição, em especial em seu artigo 150, como o princípio da legalidade, o princípio do não-confisco, o princípio da irretroatividade e da anterioridade representam salvaguardas aos indivíduos quanto ao poder de tributar na medida em que o limitam e, ao mesmo tempo, resguardam o grau de segurança jurídica necessário para tanto. Por outro lado, princípios como o princípio da solidariedade, o princípio da dignidade da pessoa humana e o princípio da igualdade revestem uma dimensão ética ao poder de tributar diferenciada. Para além dessa perspectiva, os próprios direitos sociais conquistados e assegurados pela Constituição como os em relação à educação (artigo 205), à cultura (artigo 215), à saúde (artigo 196) e diversos outros demandam, assim, uma atuação positiva do Estado para fomentar uma arrecadação fiscal a fim de implementar tais direitos em políticas públicas, por exemplo.

9 ROCHA, Antônio Sérgio Rocha. Genealogia da constituinte: do autoritarismo à democratização. São Paulo:

Lua Nova - Revista de Cultura e Política (Dossiê Constituição e Processo Constituinte), nº 88, 2013, p. 13. 
2.2 O Direito a Economia de Tributos e a Solidariedade Social

Por que devemos pagar tributos? Esta indagação é central para o estudo da tributação e para a própria existência do Estado Democrático de Direito. A tributação é uma das égides que alicerça o funcionamento do Estado, da economia e da sociedade de modo geral. Todavia, essa atividade comporta um embate, tanto no âmbito empresarial quanto ao se falar dos contribuintes como indivíduos. Discute-se muito acerca da legitimidade de um direito de empenhar-se em buscar, dentro dos limites estabelecidos pela lei, a não incidência tributária ou uma incidência menor em contraposição a um dever fundamental de pagar impostos, tendo em vista noções de justiça social, de solidariedade e das demandas sociais.

Os sistemas constitucionais modernos demonstraram a intrínseca necessidade de justificação constitucional dos critérios selecionados para a escolha das hipóteses de incidência e daqueles que se sujeitarão à tributação. Respeitáveis vozes ensejam que diante da constatação de que somente as situações previstas pelo legislador poderiam ser passíveis de tributação ${ }^{10}$. Outrossim, o contribuinte gozaria, consequentemente, de um direito de organizar seus negócios visando afastar a tributação por meio de certas estruturas. Ao buscar afastar-se da opção comum à vista de que essa constituiria fato gerador do tributo, tais estruturas alternativas não estariam dentro da hipótese de incidência tributária e, portanto, seria possível economizar tributos e livrar-se da tributação, conquanto as manifestações de capacidade contributiva fossem equivalentes. ${ }^{11}$

\footnotetext{
10 XAVIER, Alberto. Manual de Direito Fiscal. Lisboa: Faculdade de Direito de Lisboa, v.1, 1974, p.24

${ }^{11}$ SCHOUERI, Luis Eduardo (coord.). FREITAS, Rodrigo de (org.). Planejamento Tributário e o "propósito negocial". - Mapeamento de decisões do Conselho de Contribuintes de 2002 a 2008. São Paulo: Quartier Latin, 2010, p. 13
}

Assim, a elisão tributária seria uma espécie de direito subjetivo público do particular perante a ação estatal de tributação advindo da autolimitação do Estado ao formular o ordenamento jurídico. A tributação infringiria a esfera de liberdade e de propriedade do indivíduo, dessa forma, só a lei poderia dispor acerca de quais seriam os tributos e as sanções, consequentemente permitindo comportamentos que carecessem de disposição legal e de proibições. ${ }^{12}$ Nessa linha, para muito além de mero legalismo, tratar-se-ia de um verdadeiro direito firmado pelo constitucionalismo tributário consolidado através de uma série de eventos históricos que trouxeram salvaguardas ao contribuinte.

No âmbito brasileiro, portanto, a Constituição expressaria uma certeza do direito, uma estabilidade sistêmica e uma confiança legítima arraigando de forma efetiva o princípio da segurança jurídica em matéria tributária ao longo de toda aplicabilidade das competências tributárias ${ }^{13}$. Tratar-se-ia, portanto, de um direito legítimo de buscar elidir a norma e economizar tributos dentro dos estritos parâmetros legais, valendo-se, então, por exemplo, de um planejamento tributário diferenciado à luz da ausência de disposições legais aplicáveis ou de sanções para tal comportamento.

A implementação dos direitos fundamentais sociais garantidos na Constituição de 1988 tem um custo elevado. Consequentemente, requerem financiamento público, em especial, por meio dos impostos os quais representam, para os muitos que sustentam tal abordagem, um requisito indispensável para a concretização e consolidação, por exemplo, das políticas públicas instrumentalizadas a partir dos serviços

12 MALERBI, Diva Prestes Marcondes. Elisão tributária. São Paulo: Revista dos Tribunais, 1984, pp. 72-74

13 TORRES, Heleno Taveira. Direito Constitucional Tributário e Segurança Jurídica: Metódica da Segurança Jurídica do Sistema Constitucional Tributário. $2^{\text {a }}$ Ed. São Paulo: Revista dos Tribunais, 2012, pp. 298-354 
públicos. ${ }^{14}$ Destarte, o exercício de direitos pressupõe tal custo que está intimamente ligado à atividade de tributação ${ }^{15}$. Com isso, na medida em que o Estado proporciona serviços públicos à coletividade, todos os que usufruem desses serviços devem contribuir para seu custeio a partir de sua capacidade contributiva econômica. ${ }^{16}$

Partindo-se do princípio da solidariedade social presente no artigo $3^{\circ}$ da Constituição Federal de 1988 e do princípio da igualdade presente em seu artigo $5^{\circ}$, os cidadãos estariam incumbidos de pagar impostos para a construção de uma sociedade menos desigual. No âmbito jurídico, o princípio da capacidade contributiva seria um pilar para a formatação deste tipo de tributação na medida que o contribuinte cumpriria seu dever de solidariedade ao efetivamente contribuir, por meio dos tributos, para a manutenção dos gastos estatais na exata medida de sua capacidade contributiva. Em um âmbito mais sociológico e econômico, seguindo a linha de Thomas Piketty, a tributação deveria exercer, portanto, um papel de destaque na construção de uma sociedade mais justa e igualitária ${ }^{17}$. Assim, o Direito Tributário como um todo em tal concepção, deveria contribuir para a implementação da justiça social em uma ordem capitalista. ${ }^{18}$ Portanto, a arrecadação fiscal e a tributação sobre a renda seriam instrumentos fiscais para concretização das demandas sociais e para a busca de uma sociedade pautada na justiça social.

\footnotetext{
${ }^{14}$ BARCAROLLO, Felipe. O Dever Fundamental de Pagar Impostos como Condição de Possibilidade para Implementação de Políticas Públicas. Rio de Janeiro: Revista de Finanças Públicas, Tributação e Desenvolvimento (UERJ), v.1, n.1, 2013. p. 1

${ }^{15}$ HOLMES, Stephen; SUNSTEIN, Cass R. The Cost of Rights: Why Liberty Depends on Taxes. New York: W.W. Norton \& Company, 1999.

${ }^{16}$ GRECO, Marco Aurélio. Planejamento Tributário. São Paulo: Dialética, 2004, p. 282

${ }^{17}$ PIKETTY, Thomas. Capital in the Twenty-first Century. Cambridge: Harvard, 2014.
}

\section{INTERPRETAÇÃO DA NORMA E DO PLANEJAMENTO TRIBUTÁRIO}

A doutrina costuma divergir a respeito do planejamento tributário em si e de sua devida interpretação. Pode-se apontar duas correntes majoritárias: a teoria "tradicional/clássica" e a teoria "moderna". A primeira teoria é apontada por muitos como uma vertente mais "formalista" e apegada aos conceitos legais baseando-se numa certa autossuficiência desses na medida em que eles existiriam, no seu âmbito total, de forma independente à atividade interpretativa. ${ }^{19}$ Por isso, a tipicidade tributária seria cerrada, isto é, ela visaria impedir que o administrador ou o juiz intervissem na sua modelação pela via interpretativa ou integrativa. ${ }^{20}$

Essa atividade de interpretação, na corrente tradicional, é ensejada a partir da mera subsunção dos conceitos, pois, caso contrário, estar-se-ia, em linhas gerais, tributando por analogia, isto é, notase uma concepção da interpretação de cunho, de certa forma, positivista. A tipicidade, portanto, no Direito Tributário, seria fechada e conteria em si todos os elementos para valoração dos fatos e produção dos efeitos não tolerando valorações que acresçam ou substituam a contida no tipo legal. ${ }^{21}$

Dessa maneira, a teoria clássica ou tradicional, capitaneada especialmente pelo professor Alberto Xavier, é mais apegada aos princípios afeitos a uma visão liberal do Estado de Direito valorizando, em especial, a legalidade e a segurança jurídica. Assim, essa teoria observa as

${ }^{18}$ JÚNIOR, Onofre; OLIVEIRA, Ludmila; MAGALHÃES, Tarcísio. Liberalismo, Desigualdade e Direito Tributário. Belo Horizonte: Revista Brasileira de Estudos Políticos, v.1, n.110, jan./jun. 2015, p. 217

${ }^{19}$ ÁVILA, Humberto. Planejamento Tributário. Revista de Direito Tributário, v.98. São Paulo: Malheiros, 2006, p. 77

${ }^{20}$ COELHO, Sacha Calmon Navarro. Curso de Direito Tributário Brasileiro. Rio de Janeiro: Forense, 1999, p. 200. ${ }^{21}$ XAVIER, Alberto. Os Princípios da Legalidade e da Tipicidade da Tributação. São Paulo: Revista dos Tribunais, 1978, p. 92 
delimitações constitucionais como limites ao poder de tributar do Estado valorando, por consequência, as liberdades individuais como cerne do próprio constitucionalismo e das questões tributárias de modo geral.

Destarte, essa vertente enxerga um direito de economizar tributos e, logo, pressupõe sua legitimidade. Tendo em vista o aspecto peculiar da nossa Constituição de atribuir poderes a partir de regras específicas, os adeptos a essa corrente argumentam que tais regras limitam e alocam o poder estabelecendo, então, conceitos mínimos que são, na verdade, limitações oponíveis ao poder do Estado e não ferramentas do Estado para tributação. ${ }^{22}$ Assim, visando asseverar e resguardar o aspecto da segurança jurídica, a evolução desses conceitos deveria advir da modificação legislativa e não da interpretação.

Partindo-se do dilema da ambivalência principiológica do sistema constitucional brasileiro, Humberto Ávila sustenta que tal impasse deve ser revisitado a partir da apreciação da coerência sistemática ${ }^{23}$ da Carta Maior. Em vista disso, para o autor e para essa parcela da doutrina, a Constituição de 1988 privilegiaria os princípios garantistas, então, essa preferência axiológica focando-se no controle e na limitação do poder a partir de tal rigidez que estabelece regras bem definidas e que prioriza as liberdades e garantias individuais, mesmo em matéria tributária visualizando os princípios formais como o da legalidade, anterioridade e proibição de confisco acima da própria da capacidade contributiva.

Por fim, cabe ressaltar que, para tal corrente, o princípio da capacidade contributiva corresponderia a uma mera norma programática e,

\footnotetext{
${ }^{22}$ ÁVILA, Humberto. Planejamento Tributário. Revista de Direito Tributário, v.98. São Paulo: Malheiros, 2006, pp. 80-81

23 ÁVILA, Humberto. Planejamento Tributário. Revista de Direito Tributário, v.98. São Paulo: Malheiros, 2006, pp. 80-81

${ }^{24}$ XAVIER, Alberto. Tipicidade da tributação, simulação e norma antielisiva. São Paulo: Dialética, 2001, p. 104
}

por consequência, não teria força vinculante positiva, servindo, então, como parâmetro para verificar a inconstitucionalidade das leis instituidoras de impostos, caso essas negassem tal princípio. Destarte, o princípio teria uma eficácia negativa que se evidenciaria em situações nas quais, por exemplo, se buscasse instaurar imposto onde não houvesse capacidade contributiva. ${ }^{24}$

Não obstante, a partir da ascensão de conceito jurídicos indeterminados e da ascensão de novos princípios norteadores do ordenamento jurídico como o princípio da dignidade da pessoa humana e o princípio da solidariedade social, a vertente teórica "clássica" começou a ser vista como conservadora, formalista e individualista. Desse modo, formulou-se a teoria dita como "moderna" do planejamento tributário que buscou refutar a mera subsunção de conceitos e visa implementar uma constante ponderação de princípios de valores.

Assim, formada por grandes expoentes ${ }^{25}$, esta vertente defende que a Constituição Cidadã dá maior enfoque aos direitos sociais, inclinandose, por conseguinte, a uma visão de Estado mais próxima ao Estado Social. A partir do paradigma da solidariedade, da capacidade contributiva e da centralidade do princípio da dignidade da pessoa humana, o poder de tributar não deve ser visto como um limite, mas, sim, como uma função do Estado para concretizar as demandas sociais necessárias e previstas.

25 Para um panorama geral das teorias de interpretação/aplicação da norma tributária, especialmente a partir da negação ou afirmação da categoria de "elisão fiscal abusiva" (abusive tax avoidance), Cf. GODOI, Marciano de; SALIBA, Luciana Goulart Ferreira. Interpretação e aplicação da lei tributária. In: MACHADO, Hugo de Brito (Coord.). Interpretação e aplicação da lei tributária. São Paulo: Dialética, 2010, p. 285 
Partindo-se, assim, de uma noção de justiça tributária $^{26}$, essa corrente teórica e, em especial, Marco Aurélio Greco, acredita que como a Constituição Federal de 1988 passa a se tornar uma "Constituição da Sociedade brasileira" e não mais do Estado, a reflexão acerca do planejamento tributário deve ser delineada a partir da centralidade da capacidade contributiva e do seu papel na sociedade. Para tanto, à luz do constitucionalismo moderno, demonstrar-se-ia que, muito além de mera limitação do exercício do poder do Estado, a Constituição brasileira visaria assegurar direitos individuais e coletivos cabendo ao Estado o dever de concretizar e construir essa realidade ${ }^{27}$, materializando, assim, esses direitos por meio da tributação.

Dessa maneira, o contribuinte, mesmo agindo de forma lícita e válida, não poderia agir como bem entendesse, pois deveria passar por uma espécie de crivo de solidariedade social em vista de sua capacidade contributiva ${ }^{28}$. Partindose de uma concepção da eficácia positiva das normas programáticas ${ }^{29}$ e da busca da maior eficácia possível dos princípios constitucionais, toma-se uma posição em que se almeja extrair a máxima amplitude da capacidade contributiva visando assegurá-la uma eficácia positiva. A capacidade contributiva, portanto, seria a expressão valorativa da participação tributária do contribuinte. Logo, importa dizer:

A visualização do princípio da capacidade contributiva na sua dimensão do princípio da solidariedade, do princípio republicano e do princípio da igualdade, o que significa vislumbrá-lo sob a ótica do dever imputado, como regra, a todos, de concorrer para a manutenção do Estado $^{30}$.

\footnotetext{
26 UCKMAR, Victor. Princípios comuns de Direito Constitucional Tributário, $2^{a}$ edição. São Paulo: Malheiros, 1999, p. 78.

${ }^{27}$ GRECO, Marco Aurélio. Planejamento Tributário. São Paulo: Dialética, 2004, pp. 303-304.

${ }^{28}$ GRECO, Marco Aurélio. Planejamento Tributário. São Paulo: Dialética, 2004, p. 281

${ }^{29}$ AFONSO DA SILVA, José. Aplicabilidade das normas constitucionais. São Paulo: RT, 1968, p.161
}

Essa discussão ganha importância e se irradia para o embate acerca da regulação da norma antielisiva no Brasil, da dinâmica da elisão fiscal e dos próprios parâmetros do combate ao planejamento tributário. Para esta vertente exposta como clássica, a elisão fiscal e o planejamento tributário seriam a concretização de um direito legítimo do contribuinte de buscar, dentro dos limites legais, a economia de tributos.

Tal direito estaria exposto à vista de que as normas que impõem a tributação do contribuinte seriam normas de rejeição social, ou seja, a partir da crescente interferência do Estado na liberdade dos cidadãos, o indivíduo aceitaria tal norma por não ter outra alternativa e a cumpriria em face da existência de uma sanção à desobediência. ${ }^{31} \mathrm{O}$ planejamento tributário, portanto, deveria ser coibido pelo fisco apenas em casos que fugisse-se dos parâmetros legais como na simulação.

Por sua vez, a teoria moderna observaria o planejamento tributário sob a óptica da igualdade e da isonomia na qual, para os adeptos a essa vertente, em diversos casos, distorce a situação de aplicação da lei tributária implicando numa vantagem fiscal e concorrencial ao contribuinte que realizou tal planejamento ferindo a visão de que todos deveriam ficar na mesma situação perante o Fisco. ${ }^{32}$

Não somente os indivíduos, mas as empresas, também, deveriam observar considerações éticas que fizessem com que os negócios fossem para além do que está meramente requerido no texto da lei. Segundo Ricardo Lobo Torres, "o direito tributário deixase também sensibilizar-se pela ética, seja no

30 OLIVEIRA, Ricardo Rachid de. A Relevância Penal da Inadimplência Tributária. Curitiba: Juruá, 2013, p. 73.

${ }^{31}$ MARTINS, Ives Gandra. Elisão e evasão fiscal. V.13. São Paulo: Revista dos Tribunais, 1988, p. 30.

32 GRECO, Marco Aurélio. Planejamento Tributário. São Paulo: Dialética, 2004, p. 311 
plano abstrato da justiça fiscal, seja no específico da aplicação das normas tributárias e do combate à elisão fiscal" ${ }^{\prime 3}$.

Conceitos como o "Corporate Social Responsability" reintroduziriam, para tal visão, em âmbito internacional, a ética na tributação do âmbito empresarial fazendo com que as empresas devessem realizar seus negócios e empreendimentos fiscais de acordo com os interesses da comunidade e levando em conta, por exemplo, seu papel e seus impactos ambientais, econômicos e sociais na sociedade como um todo. $^{34}$

\section{UM ESTUDO DE CASO SOBRE OS LUCROS AUFERIDOS NO EXTERIOR EM VIRTUDE DE PARTICIPAÇÃO SOCIETÁRIA}

Ao analisar a jurisprudência administrativa brasileira, especialmente no âmbito federal, é possível perceber uma série de equívocos e de confusões acerca da aplicação e da incorporação de institutos que visam combater o planejamento tributário. Para fins dinâmicos, denominar-se-á tal desorientação por parte dos julgadores de instabilidade jurisprudencial. Destarte, tendo em vista principalmente os postulados da teoria dita como Clássica, a segurança jurídica vem sendo extremamente debilitada prejudicando $\mathrm{o}$ contribuinte com tais indicações confusas, pois, em muitos casos, não existem bases claras para se guiar.

O referido caso envolvendo o grupo "Arcelormittal" 35 é um bom exemplo para

\footnotetext{
${ }^{33}$ TORRES, Ricardo Lobo. Planejamento Tributário: elisão abusiva e evasão fiscal. Rio de Janeiro: Elsevier, 2012, p. 23.

${ }^{34}$ GRIBNAU, Hans. Corporate Social Responsability and Tax Planning: Not by Rules Alone. Tilburg: Social \& Legal Studies, v. 24, n.2, 2015, pp. 236-237

${ }^{35}$ MINISTÉRIO DA FAZENDA - CONSELHO

ADMINISTRATIVO DE RECURSOS FISCAIS. Recurso

Voluntário: Processo n ${ }^{\circ}$ 16643.000326/2010-91 Acórdão

$\mathrm{n}^{\circ}$ 1402-001.875. $4^{\mathrm{a}}$ Câmara/ $2^{\mathrm{a}}$ Turma Ordinária. Relator:
}

evidenciar as diversas confusões entre os conceitos referenciados e aplicados pelo CARF, caso contrapostos com diversas exposições doutrinárias e até mesmo outros casos correlatos julgados, isto é, carecendo de uniformidade.

\subsection{O Caso ARCELORMITTAL}

O grupo Arcelormittal Tubarão Comercial S/A localiza-se em Vitória, no Espírito Santo. Valendo-se de estratégias de planejamento tributário, criou uma holding, CST Corportation $\mathrm{BV}$, na Holanda, país o qual o Brasil firmou tratado contra dupla tributação internacional, uma trading, SKADDEN, na Ilha da Madeira, e uma outra empresa, a CST OVERSEAS, nas Ilhas Cayman, ambas com jurisdições de tributação favorecida.

A dupla tributação internacional consiste na imposição de tributos comparáveis por mais de um Estado sobre o mesmo contribuinte, referente ao mesmo fato e ao mesmo período, normalmente, resultando de um concurso de normas sobre um mesmo fato. ${ }^{36}$ Com efeito, os contribuintes que auferem rendimentos em outros país estão sujeitos a serem tributados duas vezes: uma pelo Estado em que o contribuinte reside e outra pelo Estado que se originaram os investimentos ${ }^{37}$. Entretanto, almejando combater a pluritributação internacional de renda e de patrimônio, os Estados costumam celebrar tratados para resolver controvérsias fiscais. Para tanto, fixam as competências tributárias de cada país em relação aos fatos ocorridos em abrigo do tratado. Tais tratados são de alta relevância para o

Cons. Fernando Brasil de Oliveira Pinto. Julgado em: 26/11/2014. S1- C472 FL. 905. Impresso em: 30/06/2015 por Receita Federal.

${ }^{36}$ SANTI, Eurico Marcos Diniz de; ZILVETI, Fernando Aurélio. Tributação Internacional. São Paulo: Saraiva, 2007, p. 68 (Série GVLaw)

${ }^{37}$ VOGEL, Klaus. Problemas de interpretação em acordos de bitributação. Trad. Luis Eduardo Schoueri. In: Direito Tributário: Homenagem a Alcides Jorge Costa. Coord. Luis Eduardo Schoueri. São Paulo: Quartier Latin, 2003, p. 962 
país, pois geram fortes impactos para a receita do Estado, bem como para os investimentos estrangeiros diretos.

Cabe ao menos citar que por trás de tal caso e dos próprios tratados contra dupla tributação firmados pelo Brasil, existe uma relevante polêmica acerca da possibilidade de tributação das empresas controladas, direta ou indiretamente, mesmo no caso em que elas estejam localizadas em países que o Brasil tenha celebrado tais acordos, como a Holanda. Essa polêmica surgiu a partir da problemática de compatibilizar o artigo 74 da MP 2158-35/2001 com o artigo $7^{\circ}$ da Convenção da OCDE acerca de matérias fiscais. Essa argumentação pode ser observada, guardadas as especificidades de cada caso em concreto, em outros julgamentos do CARF como o caso NAMISA ${ }^{38}$ e o caso MARSELHA Holdings ${ }^{39}$, por exemplo.

Em sessão realizada no dia 26.11.2014, a $2^{\mathrm{a}}$ Turma Ordinária da $4^{\mathrm{a}}$ Câmara do CARF julgou recurso voluntário interposto em face de acórdão lavrado por delegacia de julgamento da Receita Federal. No caso, tratava-se de discussão sobre autos de infração de Imposto de Renda de Pessoa Jurídica e Contribuição Social sobre Lucros Líquidos, cumulados com juros e multa de ofício, relativos ao ano-calendário de 2005, em decorrência da adição ao lucro líquido de rendimentos auferidos no exterior pelas controladas direta (CST Corporation BV, com sede na Holanda) e indiretas (Arcelos Mittal Trading Ltda., à época dos fatos denominada Skadden Consultoria e Serviços Ltda., com sede em Portugal e CST Overseas, com sede nas Ilhas Cayman) da sociedade empresária recorrente.

No termo de verificação fiscal, a fiscalização não constatou propósito negocial das

38 MINISTÉRIO DA FAZENDA - CONSELHO ADMINISTRATIVO DE RECURSOS FISCAIS. Recurso Voluntário: Processo ${ }^{\circ}$ 10880.728246/201287 Acórdão 1402002.338. $\quad 4^{\mathrm{a}}$ Câmara / $2^{\mathrm{a}}$ Turma Ordinária Relator: Cons. Paulo Mateus Ciccone. Julgado em: 05/10/2016. S1C472 FL. 864. controladas, de maneira a não haver distinção entre controle direto e indireto para fins fiscais e o estabelecimento permanente apontado não possuir autonomia, o que leva a concluir que os resultados financeiros foram efetivamente realizados pela matriz localizada no Brasil.

Ademais, embora não houvesse imputação de ilícitos tributários, tais como nas hipóteses de dolo, fraude, simulação interposição fictícia e abuso de direito, verificou-se que a ausência do referido propósito negocial levou a administração tributária federal a concluir que o contribuinte estruturou-se em termos societários com vistas a utilizar o regime jurídico instituído pela Convenção Destinada a Evitar a Dupla Tributação e Prevenir Evasão Fiscal em Matéria de Imposto sobre a Renda, entre o Governo da República Federativa do Brasil e o Governo do Reino dos Países Baixos (Tratado Brasil-Holanda), internalizado no ordenamento brasileiro pelo Decreto 355, de 2 de dezembro de 1991, com a finalidade única de evitar a tributação dos lucros da atividade exercida pela controlada indireta sediada nas ilhas Cayman em desfavor da autoridade brasileira.

Em sede de contencioso administrativo, centrou-se a discussão em definir a existência de comando autorizativo na legislação nacional sobre a tributação de capital em bases universais para considerar os lucros auferidos pelas controladas indiretas da recorrente em jurisdições fiscais favorecidas, independentemente de consolidação dos resultados na controlada direta, a holandesa CST BV. Isso porque se colocou em questão se era devida a consideração dos lucros das controladas indiretas como auferidos diretamente pela matriz brasileira. Por isso, a fixação do alcance da proteção tributária

39 MINISTÉRIO DA FAZENDA - CONSELHO ADMINISTRATIVO DE RECURSOS FISCAIS. Recurso Voluntário: Processo n ${ }^{\circ} 16561.720127 / 201356$ Acórdão n ${ }^{\circ}$ 1402002.321. $\quad 4^{\mathrm{a}}$ Câmara / $2^{\mathrm{a}}$ Turma Ordinária. Relator: Cons. Fernando Brasil de Oliveira Pinto. Julgado em: 04/10/2016. S1- C472 FL. 563. 
conferida pelo Tratado Brasil-Holanda também foi debatida.

Nesse escopo, torna-se conveniente ao presente exame reproduzir o seguinte excerto do voto do Relator ad hoc:

\begin{abstract}
Mesmo sem fazer juízo de valor quanto à constituição da holding holandesa, é possível afirmar que o caso dos autos se assemelha aos casos de 'treaty shopping', conhecida forma de abusa das convenções internacionais para evitar a dupla tributação, estrutura pela qual uma pessoa jurídica residente em país que não é parte de uma convenção, utiliza-se de outra pessoa jurídica dentro de um Estado que é parte, com o objetivo de obter as vantagens dos dispositivos das convenções.

O treaty shopping é forma de abuso de direito, que viola o espírito do tratado.

Uma vez que os lucros autuados não são próprios da CST BV (Holanda), já que não foram produzidos em território holandês, mas, sim, nas Ilhas Cayman, a CST BV se mostra meramente condutora para a passagem desses lucros ao Brasil. Por via de consequência, os lucros em questão devem ser vistos como lucros da CST Overseas, sediada nas Ilhas Cayman, país que não faz parte da convenção e dela não pode se beneficiar.
\end{abstract}

A divergência no órgão colegiado deu-se quanto à necessidade de revisão do lançamento tributário, pois o Relator ad hoc entende pela necessidade da prévia consolidação vertical dos resultados na controlada holandesa, ao passo que a corrente vencedora assentou a aplicação correta do Tratado Brasil-Holanda pela Administração Tributária, ao seguinte fundamento:

[...] se demonstrado nos autos ter havido a consolidação de resultado das controladas indiretas nas controladas diretas, sendo esta desprovida de propósito negocial, $\mathrm{cm}$ o intuito exclusivo de evitar a tributação dos resultados, correta a desconsideração dos efeitos tributários daí decorrentes, e o procedimento de entender como disponibilizados diretamente na controladora no Brasil, os lucros das controladas indiretas.

40 Divide-se a doutrina a partir do embate entre consideração civil e a econômica de expressões homônimas do Direito Privado pelo Direito Tributário. Pela consideração econômica, vide: SCHOUERI, Luís Eduardo.
Nessa linha, o aspecto do planejamento tributário começou a ser combatido em razão de institutos que não possuem lastro legislativo, bem como não dizem respeito ao próprio direito tributário.

No julgamento em exame, observa-se linha argumentativa que privilegia tais categorias privadas mesmo em situações complexas, expressamente, diferentes ou misturando os conceitos, bem como os utilizando de modo diferente em situações semelhantes. Por certo, é comum a legislação tributária apropriar-se de terminologias do Direito Privado, inclusive com a alteração completo do significado do mesmo significante para fins tributários.

A problemática inicia-se com o emprego pelo legislador de expressões cediças no âmbito civilista, sem maiores ressalvas, pois impende perquirir se há obrigatoriedade de uniformidade hermenêutica em ambos os ramos jurídicos. Em outras palavras, é emblemática no Direito Tributário se as mesmas expressões denotam os mesmos significados, com vinculação do intérprete na omissão do criador da norma tributária. ${ }^{40}$ Nesses termos, sustenta-se que a incorporação de conceitos e tipos do direito comparado devem ser vistos de forma analítica pela dogmática tributária.

No particular, veja-se que a noção de propósito negocial, derivado da business purpose doctrine, nos EUA, questiona se a transação ganhou um relevo específico exclusivamente por razões fiscais ou, que sob a óptica empresarial, a formatação dessa estrutura societária não faria sentido, caso não fossem seus benefícios fiscais.

Malgrado, tal critério é passível de críticas por dois motivos. Primeiramente, a introdução de critérios estrangeiros de forma direta e sem maior reflexão ou "tradução" legislativa deve ser vista

Direito Tributário. 5 ed. São Paulo: Saraiva, 2015, pp. 743747. Pela consideração civilista, confira-se: BOZZA, Fábio Piovesan. Planejamento Tributário e Autonomia Privada. São Paulo: Quartier Latin, 2015, p. 72. 
com extrema cautela, pois, como já exposto, o sistema tributário brasileiro é muito particular, especialmente se comparado com países de common law como os EUA. Além disso, cabe a reflexão se a adoção de tal critério não incidiria em uma mera "interpretação econômica" na qual se enseja observar as implicações econômicas da norma tributária, haja vista sua natureza intrinsecamente econômica. À luz do princípio da legalidade, é preciso repensar se a interpretação de conteúdo, isto é, acerca do "espírito da lei" ou do seu real propósito, poderia superar o comando expresso na lei, alargando-o para tributar estruturas simplesmente por não se adequarem a certas consequências econômicas, com algum grau de arbítrio.

Outro exemplo extraído do voto refere-se à identificação automática do treaty shopping como conceito de direito internacional privado à tradicional figura civilista do abuso de direito. ${ }^{41} \mathrm{O}$ treaty shopping, na verdade, diz respeito ao processo de escolha (shopping) de países que tenham firmado algum tratado que favoreça o aspecto da tributação para, então, firmar estruturas, como, por exemplo, controladas, nesses países, beneficiando-se do ponto de vista fiscal e visando apenas tais benefícios fiscais.

Por sua vez, o abuso de direito está definido no artigo 187 do Código Civil e consiste, em linhas gerais, ao excesso, pelo titular, no exercício regular de um direito ${ }^{42}$. Desse modo, há um desvio de finalidade dos fins econômicos e sociais destinados, normalmente, a tal direito. De fato, a principal funcionalidade de uma norma geral antielisão em dado ordenamento jurídico consiste em possibilitar a instituição de uma fronteira entre o uso e o abuso do direito de planejamento tributário. ${ }^{43}$

\footnotetext{
41 Em sentido contrário ao aqui defendido, veja-se: TORRES, Ricardo Lobo. Planejamento Tributário: elisão abusiva e evasão fiscal. Rio de Janeiro: Elsevier, 2012, p. 82-83.

${ }^{42}$ FAJERSZTAJN, Bruno. Caso Josapar: Reflexão sobre a chamada incorporação às avessas à luz de um caso típico de
}

Logo, o juízo técnico mostrou-se impreciso, assim como o uso do termo "espírito do tratado", tendo em vista que se trata de comando normativo excessivamente vago para uma discussão de tamanha complexidade técnica. Ou seja, o caso em questão demonstra que os conceitos que, para além da controvérsia da possibilidade de sua utilização, foram colocados em situações que deveriam ter sido resolvidas a partir de parâmetros mais claros, técnicos e coerentes, assim, consequentemente, prejudicou-se a organização do contribuinte.

\subsection{A Instabilidade Jurisprudencial no Âmbito Contencioso Administrativo}

O antigo Conselho de Contribuintes (CC) tornou-se o atual Conselho Administrativo de Recursos Fiscais (CARF) com a edição da Medida Provisória 449/2008, posteriormente convertida na Lei 11.941/2009. Por outro lado, após meados da década de 90 do século passado, a administração tributária federal passou a rejeitar diversas estruturas societárias internacionais criadas pelos contribuintes que visavam afastar ou diminuir a incidência tributária em jurisdição brasileira. Dessa forma, a literatura tributária dá conta de instabilidade jurisprudencial no bojo do contencioso administrativo federal desde o $\mathrm{CC}$ ao CARF, notadamente em temas caros ao direito tributário internacional, como, por exemplo, a exigência de propósito negocial, âmbito de aplicação de convenções internacionais sobre dupla tributação e critérios de presença substancial e autonomia empresarial para conexão da legislação tributária aplicável.

Após a análise comparativa da jurisprudência administrativa do CARF pela

simulação. In: CASTRO, Leonardo Freitas de Moraes (Coord.). Planejamento Tributário: Análise de Casos. $3^{\mathrm{a}}$ ed. São Paulo: MP Editora, v.3, 2014, p. 268

${ }^{43}$ MACHADO, Hugo de Brito. Introdução ao Planejamento Tributário. São Paulo: Malheiros, 2014, p. 125-126. 
ferramenta do normative systems, Luís Eduardo Schoueri demonstra que embora a falta de propósito negocial se revelasse como a efetiva razão para a recusa do planejamento, caso seguisse precedentes semelhantes, os julgadores procuravam justificar sua decisão com base em teorias como o abuso de direito, a fraude à lei e o negócio indireto, chegando-se à situação paradoxal de que circunstâncias semelhantes eram afastadas, por fundamentos diferentes ${ }^{44}$. Além disso, a pesquisa aponta para a necessária e urgente compatibilização da jurisprudência administrativa com a atividade legislativa, para que as posteriores decisões sejam balizadas pela lei.

Mary Elbe Queiroz demonstra que, na falta de uma norma geral antiabuso e a partir do manejo abusivo do planejamento tributário por parte de certos contribuintes, foi surgindo, gradualmente, um "ativismo administrativo", todavia prejudicial e perigoso. A jurisprudência administrativa tem invocado e manejado os institutos jurídicos de forma fluída e sem uniformidade a partir de critérios subjetivos e variáveis, enquadrando certas estruturas ora como abuso de direito, ora como fraude à lei. Assim, sua pesquisa aponta a falta de critérios para justificar a existência de "planejamentos tributários abusivos", de modo que se nota ausência de uniformidade na ratio decidendi dos precedentes analisados pela pesquisa ${ }^{45}$ para invalidar certas estruturas sob a égide do sistema tributário brasileiro, bem como apontando o uso indistinto de tais institutos que visam combater o planejamento tributário.

Com espeque nesses elementos teóricos e empíricos, comunga-se da interpretação de Ataíde

\footnotetext{
${ }^{44}$ SCHOUERI, Luis Eduardo (coord.). FREITAS, Rodrigo de (org.). Planejamento Tributário e o "propósito negocial". - Mapeamento de decisões do Conselho de Contribuintes de 2002 a 2008. São Paulo: Quartier Latin, 2010.

${ }^{45}$ QUEIROZ, Mary Elbe. Novos horizontes da tributação um diálogo luso brasileiro. Coimbra: Almedina, 2012, pp. 478-481

46 MARCELINO JÚNIOR, Ataíde. Caso Eagle 1: interpretação das normas brasileiras de tributação de lucros
}

Marcelino Júnior acerca dos reflexos do caso Eagle, utilizado como precedente no julgado aqui analisado, sobre a matéria dos lucros auferidos no exterior por controladas e coligadas de sociedade empresária brasileira, na compreensão iterativa do CARF, de modo a encontrar-se em um novo paradigma de interpretação dos tratados de bitributação no Brasil. ${ }^{46}$

Revela-se, portanto, imperativa à dogmática tributária refletir sobre as evoluções jurisprudenciais acerca da temática e seus reflexos no relacionamento entre a tributação e a ordem econômica, à luz da Constituição da República de 1988.

\section{CONSIDERAÇÕES FINAIS}

Em um Estado Democrático de Direito, não se deve partir de uma percepção de mera divergência entre princípios tidos como opostos, mas, sim, de uma noção de complementariedade. Princípios "opostos" são, na realidade, complementares e constitutivos da integridade complexa inerente à aplicação do Direito, isto é, é importante perceber a produtividade das tensões principiológicas. No âmbito jurídico, portanto, é preciso levar em conta a história constitucional e institucional por trás dos direitos conquistados pelos cidadãos e sempre observar o ordenamento como uma construção sistêmica e coerente ${ }^{47}$.

A questão principal não diz respeito meramente à filiação a um tipo de visão acerca do papel e do alcance do Estado em matéria tributária. Para além de mero juízo político, no âmbito técnico-jurídico, nota-se a difusão de ordenamentos com alta carga principiológica e

e rendimentos oriundos do exterior pelo CARF. In: MORAES, Leonardo Freitas de (org.). Tributação internacional: analise de casos. São Paulo: MP, 2010, p. 277.

47 CARVALHO NETTO; Menelick de; SCOTTI, Guilherme. Os direitos fundamentais e a (in)certeza do direito: a produtividade das tensões principiológicas e a superação do sistema de regras. Belo Horizonte: Fórum, 2011. 
axiológica, bem como uma crescente liberdade do julgador no processo de densificação de tais princípios no caso concreto em contraposição com o processo de mera subsunção. Destarte, é preciso que haja, para se manter um grau mínimo de segurança jurídica aos destinatários do ordenamento, uma argumentação jurídica coerente, bem fundamentada e racionalizada ${ }^{48}$, pois a estabilização das expectativas e a própria segurança jurídica advém da vinculação do intérprete pelo texto ${ }^{49}$.

À luz de uma série de direitos fundamentais conquistados a partir da autolimitação do Estado e de liberdades individuais estendidas ao contribuinte contra a ação estatal, a implementação da teoria Moderna de maneira absoluta e irrestrita, como vem sendo feita hoje, aliada a uma confusão jurisprudencial especialmente na esfera administrativa faz com que se inviabilize a prática do planejamento tributário. Obviamente, essa teoria trouxe diversas contribuições importantes em especial na visão da redução de desigualdades e do caráter essencial do Direito Tributário na concretização de demandas sociais, mas, haja vista a maneira que é aplicada, hoje, pelos julgadores, ultrapassa, em diversos casos, a legitimidade do Estado na tributação. Na medida em que há sua adoção irrestrita e sem alicerce legislativo, impossibilitase o empreendimento do planejamento tributário, pois se tributa e se desconsidera diversos arranjos elaborados pelo contribuinte visando a economia de tributos. No entanto, sem parâmetros coerentes e a partir de institutos como o treaty shopping ou o propósito negocial, também, sem lastro legislativo e de forma confusa e incoerente.

Dentro do escopo de ações de caráter lícito, o contribuinte deve poder agir de maneira a não considerar consequências ou custos fiscais. A dita economia de opção ou economia de tributos é um direito que todo cidadão deveria gozar na medida em que se coloca numa posição juridicamente livre e lícita ${ }^{50}$. Cabe ressaltar que o planejamento tributário não é evasão fiscal, bem como não é fraude à lei, trata-se de atuar dentro dos estritos limites legais. Existe um direito fundamental de buscar a economia de tributos, bem como de exigir que a tributação seja feita nos limites legislativos respeitando as salvaguardas do contribuinte perante o Estado.

Não se trata, assim, da adoção irrestrita de uma teoria ou de outra, mas, sim, de compatibilizá-las para que a tributação ocorra de forma ponderada e clara. Assim como, apesar de certa desconfiança acerca de alguns institutos, na hipótese de sua adoção, deve-se emprega-los de forma clara, uniforme, fundamentada e precisa para que o contribuinte possa atuar a partir de tais bases. Dessa forma, o grande intuito desta crítica diz respeito à garantia da segurança jurídica ao contribuinte no que toca a possibilidade do planejamento tributário.

Logo, o CARF precisa desenvolver sua linha jurisprudencial com coerência, de modo que o contribuinte possa ter parâmetros sólidos para realizar seu planejamento tributário. Conclui-se, ainda, pela necessidade de uma reflexão acerca da incorporação de institutos e das teorias doutrinárias hauridos do direito comparado.

\section{REFERÊNCIAS}

AFONSO DA SILVA, José. Aplicabilidade das normas constitucionais. São Paulo: RT, 1968.

48 GOODRICH, Peter. Legal Discourse: Studies in Linguistics, Rhetoric and Legal Analysis. Edimburgo: University of Edimburg, 1984, p. 103

${ }^{49}$ GRAU, Eros Roberto. Interpretação da lei tributária de segurança jurídica. Revista de Direito Tributário, v.113, 2011, p. 223
${ }^{50}$ FERREIRO LAPATZA, José Juan. Direito Tributário: teoria geral do tributo. Trad. Roberto Barbosa Alves. São Paulo: Manole; Espanha: Marcial Pons, 2007, p. 92 
ATALIBA, Geraldo. Sistema Constitucional Tributário Brasileiro. São Paulo: Revista dos Tribunais, 1968.

ÁVILA, Humberto. Planejamento Tributário. Revista de Direito Tributário, v.98. São Paulo: Malheiros, 2006.

BARCAROLLO, Felipe. O Dever Fundamental de Pagar Impostos como Condição de Possibilidade para Implementação de Políticas Públicas. Rio de Janeiro: Revista de Finanças Públicas, Tributação e Desenvolvimento (UERJ), v.1, n.1, 2013.

BOZZA, Fábio Piovesan. Planejamento Tributário e Autonomia Privada. São Paulo: Quartier Latin, 2015.

CARRAZA, Roque Antônio. Curso de Direito Constitucional Tributário. $28^{\mathrm{a}}$ ed. São Paulo: Malheiros, 2012.

CARVALHO NETTO; Menelick de; SCOTTI, Guilherme. Os direitos fundamentais e a (in)certeza do direito: a produtividade das tensões principiológicas e a superação do sistema de regras. Belo Horizonte: Fórum, 2011.

COELHO, Sacha Calmon Navarro. Curso de Direito Tributário Brasileiro. Rio de Janeiro: Forense, 1999.

FAJERSZTAJN, Bruno. Caso Josapar: Reflexão sobre a chamada incorporação às avessas à luz de um caso típico de simulação. In: CASTRO, Leonardo Freitas de Moraes (Coord.). Planejamento Tributário: Análise de Casos. $3^{\mathrm{a}}$ ed. São Paulo: MP Editora, v.3, 2014

FERREIRO LAPATZA, José Juan. Direito Tributário: teoria geral do tributo. Trad. Roberto Barbosa Alves. São Paulo: Manole; Espanha: Marcial Pons, 2007.

GOODRICH, Peter. Legal Discourse: Studies in Linguistics, Rhetoric and Legal Analysis. Edimburgo: University of Edimburg, 1984.

GRAU, Eros Roberto. Interpretação da lei tributária de segurança jurídica. Revista de Direito Tributário, v.113, 2011.

GRIBNAU, Hans. Corporate Social Responsability and Tax Planning: Not by Rules Alone. Tilburg: Social \& Legal Studies, v. 24, n.2, 2015.

GRECO, Marco Aurélio. Planejamento Tributário. São Paulo: Dialética, 2004.

HOLMES, Stephen; SUNSTEIN, Cass R. The Cost of Rights: Why Liberty Depends on Taxes. New York: W.W. Norton \& Company, 1999.

JÚNIOR, Onofre; OLIVEIRA, Ludmila; MAGALHÃES, Tarcísio. Liberalismo, Desigualdade $e$ Direito Tributário. Belo Horizonte: Revista Brasileira de Estudos Políticos, v.1, n.110, jan./jun. 2015. 
MACHADO, Hugo de Brito. Proibição da guerra fiscal e a redução das desigualdades regionais. In: ROCHA, Valdir de Oliveira (org). Grandes questões atuais do Direito Tributário. $15^{\circ}$ volume. São Paulo: Dialética, 2011.

. Introdução ao Planejamento Tributário. São Paulo: Malheiros, 2014.

MALERBI, Diva Prestes Marcondes. Elisão tributária. São Paulo: Revista dos Tribunais, 1984.

MARCELINO JÚNIOR, Ataíde. Caso Eagle 1: interpretação das normas brasileiras de tributação de lucros e rendimentos oriundos do exterior pelo CARF. In: MORAES, Leonardo Freitas de (org.). Tributação internacional: analise de casos. São Paulo: MP, 2010.

GODOI, Marciano de; SALIBA, Luciana Goulart Ferreira. Interpretação e aplicação da lei tributária. In: MACHADO, Hugo de Brito (Coord.). Interpretação e aplicação da lei tributária. São Paulo: Dialética, 2010.

MARTINS, Ives Gandra. Elisão e evasão fiscal. V.13. São Paulo: Revista dos Tribunais, 1988.

MINISTÉRIO DA FAZENDA - CONSELHO ADMINISTRATIVO DE RECURSOS FISCAIS. Recurso Voluntário: Processo $n^{\circ} 16643.000326 / 2010-91$ Acórdão n ${ }^{\circ} 1402-001.875 .4^{\mathrm{a}}$ Câmara/ $2^{\mathrm{a}}$ Turma Ordinária. Relator: Cons. Fernando Brasil de Oliveira Pinto. Julgado em: 26/11/2014. S1- C472 FL. 905. Impresso em: 30/06/2015 por Receita Federal.

MINISTÉRIO DA FAZENDA - CONSELHO ADMINISTRATIVO DE RECURSOS FISCAIS. Recurso Especial do Contribuinte: Processo n 11080.72233007 /2012-06 Acórdão n 9101-002.429. $1^{\text {a }}$ Turma Ordinária. Relator: Cons. Marcos Aurélio Pereira Valadão. Julgado em: 18/08/2016. S1C472 FL. 562. Impresso em: 04/10/2016 por Receita Federal.

MINISTÉRIO DA FAZENDA - CONSELHO ADMINISTRATIVO DE RECURSOS FISCAIS. Recurso Voluntário: Processo $\mathrm{n}^{\circ} \quad 10880.728246 / 201287$ Acórdão 1402002.338. $4^{\mathrm{a}}$ Câmara / $2^{\mathrm{a}}$ Turma Ordinária Relator: Cons. Paulo Mateus Ciccone. Julgado em: 05/10/2016. S1C472 FL. 864.

MINISTÉRIO DA FAZENDA - CONSELHO ADMINISTRATIVO DE RECURSOS FISCAIS. Recurso Voluntário: Processo $\mathrm{n}^{\circ} \quad 16561.720127 / 201356$ Acórdão $\quad \mathrm{n}^{\circ} \quad 1402002.321$. $4^{\mathrm{a}}$ Câmara / $2^{\mathrm{a}}$ Turma Ordinária. Relator: Cons. Fernando Brasil de Oliveira Pinto. Julgado em: 04/10/2016. S1- C472 FL. 563.

PIKETTY, Thomas. Capital in the Twenty-first Century. Cambridge: Harvard, 2014.

QUEIROZ, Mary Elbe. Novos horizontes da tributação - um diálogo luso brasileiro. Coimbra: Almedina, 2012

ROCHA, Antônio Sérgio Rocha. Genealogia da constituinte: do autoritarismo à democratização. São Paulo: Lua Nova - Revista de Cultura e Política (Dossiê Constituição e Processo Constituinte), n 88 , 2013.

SCHOUERI, Luis Eduardo (coord.). FREITAS, Rodrigo de (org.). Planejamento Tributário e o "propósito negocial". Mapeamento de decisões do Conselho de Contribuintes de 2002 a 2008. São Paulo: Quartier Latin, 2010. 
Direito Tributário. 5 ed. São Paulo: Saraiva, 2015,

SANTI, Eurico Marcos Diniz de; ZILVETI, Fernando Aurélio. Tributação Internacional. São Paulo: Saraiva, 2007. (Série GVLaw)

TORRES, Heleno Taveira. Direito Constitucional Tributário e Segurança Jurídica: Metódica da Segurança Jurídica do Sistema Constitucional Tributário. $2^{a}$ Ed. São Paulo: Revista dos Tribunais, 2012.

TORRES, Ricardo Lobo. Planejamento Tributário: elisão abusiva e evasão fiscal. Rio de Janeiro: Elsevier, 2012.

UCKMAR, Victor. Princípios comuns de Direito Constitucional Tributário. $2^{\mathrm{a}}$ edição. São Paulo: Malheiros, 1999.

VOGEL, Klaus. Problemas de interpretação em acordos de bitributação. Trad. Luis Eduardo Schoueri. In: Direito Tributário: Homenagem a Alcides Jorge Costa. Coord. Luis Eduardo Schoueri. São Paulo: Quartier Latin, 2003.

XAVIER, Alberto. Manual de Direito Fiscal. Lisboa: Faculdade de Direito de Lisboa, v.1, 1974. 1978. . Os Princípios da Legalidade e da Tipicidade da Tributação. São Paulo: Revista dos Tribunais, . Tipicidade da tributação, simulação e norma antielisiva. São Paulo: Dialética, 2001.

Recebido em: 12/12/2016

Aceito em: 11/03/2017 
